\title{
Burnout, Psychiatric Symptoms and Social Adjustment among Military Personnel
}

\author{
Ahmed Elafandy', Ashraf El-Tantawy ${ }^{2}$, Magid Bahi Eldin³, Haydy H. Sayed ${ }^{*}$ \\ ${ }^{1}$ Psychiatric Resident at Military Hospitals, Egypt, 2Department of Psychiatry \& Neurology, Faculty of Medicine, \\ Suez Canal University, Egypt, and '3epartment of Psychiatry, Military Medical Academy, Egypt
}

\begin{abstract}
Background: Physically dangerous work, such as that of first responders and military personnel, is known to have adverse health consequences even for those who are not injured or killed. Military services have always been one of the most challenging and stressful services everywhere. Aims: To assess the burnout, psychiatric symptoms, and social adjustment among military personnel in early military services. Subjects and Methods: A cross-sectional study on 150 soldiers from mental health military hospital, serving the soldiers recently enrolled in military services through military training units all over Egypt, for one year period. Every person was assigned for: The socio-demographic data, The Maslash Burnout Inventory, The Symptom Checklist-90-R, and the social Readjustment Rating Scale. Results: On screening by $\mathrm{MBI}$, the soldiers got a score of $31.79 \pm 16.81$. So, they were found to be having psychological distress. The socio-demographic variables showed no significant association with psychological stress. The Symptom Checklist-90-R showed high levels of interactive sensitivity, anxiety, phobic anxiety, paranoid ideation, and psychoticism. As measured by Pearson's correlation coefficient, there was evidence of a linear association between anxiety, depression and paranoia, and the Social Readjustment Scale as well. Conclusions: The social readjustment for the psychosocial stress and psychological symptoms of the military services have a significant role in the life of the military personnel and their integration into military life. Rigorous planning, preparation, and implementation of training before the task to prevent the occurrence of psychiatric symptoms are considered necessary.
\end{abstract}

Keywords: Burnout, Psychiatric, Social Adjustment, Military

\section{Introduction}

Military personnel are at a high risk of exposure to potentially traumatic events. The impact of mental health on decision making is especially of significance given the high technology, fast-paced warfare of the $21^{\text {st }}$ century, the battlefield which leaves little margin for error ${ }^{(1)}$. The high risk make the military personnel vulnerable to suffering from psychological distress and mental health problems including depression, family violence, substance abuse, and posttraumatic stress disorder (PTSD), all of which are problems for the military services and a threat to occupational functionality ${ }^{(2,3)}$. Military services have always been one of the most challenging and stressful services in everywhere and with changing times it is becoming even more so. Soldiers must deal with all work and training and even traumatic events without losing their composure and sensitivity. They must face potentially hazardous situations that can

*Corresponding Author: drhaydy@yahoo.com 
result in physical or mental trauma or even death in the line of duty. Their work stress can be further aggravated because of their wrong coping methods. Most international studies have found high stress levels in military services, which is disturbing as psychiatric morbidity in military personnel can have many direct and indirect negative consequences for society. Therefore, apart from physical fitness, they have to be mentally fit to do their duties ${ }^{(4-9)}$. Burnout Syndrome (BOS) is a psychological term for the experience of long-term exhaustion and diminished interest. It is often observed in work-related stress as for example, among general practitioners, teachers, social service employees, police, and military men. Burnout is recognized in the International classification of diseases10 as 'problems related to life management difficult' although it is not recognized in $\operatorname{DSM}^{(10,11)}$. The characteristics of the BOS are emotional exhaustion, depersonalization and reduced personal satisfaction ${ }^{(12)}$. The consequences of burnout are potentially very serious, which suggest that burnout can lead to deterioration in the quality of work or service that is provided by the staff. It appears to be a factor in job turnover, absenteeism, and low morale. Furthermore, burnout seems to be correlated with various self-reported indices of personal distress, increased use of alcohol and drugs, and marital and family problems ${ }^{(13)}$. However, although most of the military personnel are exposed to the same external occupational and organizational stressors, all of them do not develop psychological morbidity. This is because a person's vulnerability to stress is also based on an individual's appraisal and response to difficult situations. Personality and coping both play an interactive and independent role in influencing adjustment to stress ${ }^{(14)}$. A study on military aviation crew, found neuroticism as a personality trait in correlation to job-related stress and concluded that stress evaluation and certain personality characteristics examination can be used for the development of basic antistress programs and measures ${ }^{(15)}$. Coping styles and methods are very important in resilience from burnout and its psychological morbidity. Social readjustment using active problem solving is the highest statistically significant as effectiveness among other coping methods ${ }^{(16)}$. As there are few studies in this regard in Egypt, this study is an attempt to explore the relationship between psychiatric symptoms, social readjustment and burnout among military personnel in early military services. This can also be a useful guide to reduce psychological stress to ensure that the military personnel feel physically and mentally competent to do its duty efficiently and alertly.

\section{Subjects and Methods}

A cross-sectional study on 150 soldiers from mental health military hospital, serving the soldiers recently enrolled in military services through military training units, allover Egypt, for one year period. The military personnel were selected randomly from day one of their enrolment in the military services. Their age ranged 18 to 30 years old with average intelligence (IQ $\geq$ 90). Soldiers with history of any psychiatric disorder or having any physical or neurological disease were excluded. They had clinical assessment: I- Socio demographic data, (Age, Sex, nationality, education, and marital status, etc.). II- Clinical Examination: A complete physical and neurological examination to exclude neurological or organic co-morbidities. III. Study Tools; Every person was assigned for the following tools: A) The Maslach Burnout Inventory $(\mathrm{MBI})$ : The original form of the $\mathrm{MBI}$ was constructed by Maslash, et al., with the goal to assess an individual's experience of burnout. The MBI consists of 22 questions to assess three dimensions of burnout: 
emotional exhaustion, depersonalization, and personal accomplishment. Emotional exhaustion entails feelings of work-induced emotional overextension and exhaustion. Sample items include work-induced feelings of emotional drain, fatigue, strain, and feeling used up or frustrated ${ }^{(17)}$. Depersonalization refers to 'unfeeling and impersonal' attitudes toward the physician practices. The 22-item $\mathrm{MBI}$ required a 7point rating scale for each item ( $0=$ never, 7 = every day). The MBI takes between 1015 minutes to complete and can be administered to individuals or groups. The inventory was translated and validated into Arabic by Amin \& Mohammad.and used in this study(8). B) The Symptom Checklist-90-R (SCL-90-R): It is a relatively brief self-report psychometric questionnaire published by the Clinical Assessment division of the Pearson Assessment \& Information group. It is designed to evaluate a broad range of psychological problems and symptoms of psychopathology. It is also used in measuring the progress and outcome of psychiatric and psychological treatments or for research purposes. According to the overview given by the publisher, the SCL-90-R is normed on individuals 13 years and older. It consists of 90 items and takes 12-15 minutes to administer, yielding nine scores along primary symptom dimensions and three scores among global distress indices. The primary symptom dimensions that are assessed are somatization, obsess-ivecompulsive, interpersonal sensitivity, depression, anxiety, hostility, phobic anxiety, paranoid ideation, psychoticism, and a category of "additional items" which helps clinicians assess other aspect of the client's symptoms (e.g., item 19, "poor appetite"). The three indices are global wellness index, hardiness, and symptom free. A high number of studies have been conducted demonstrating the reliability, validity, and utility of the instrument. It is one of the most widely used measures of psychological distress in clinical practice and research $^{(18)}$. The Arabic version used in the study was translated and validated in the Egyptian by Al-Behairy ${ }^{(19)} \mathrm{C}$ ) The Social Readjustment Rating Scale (SRRS): It was developed by Holme's \& Rahe, to identify major stressful life events. Each one of the 43 stressful life events was awarded a Life Change Unit depending on how traumatic it was felt to be by a large sample of participants. A total value for stressful life events can be worked out by adding up the scores for each event experienced over a 12month period. If a person has less the 150life change units, they have a $30 \%$ chance of suffering from stress. 150-299 life change units equate to a $50 \%$ chance of suffering from stress. Over 300 life units means a person has an $80 \%$ chance of developing a stress related illness ${ }^{(20)}$.

\section{Statistical Analysis}

Data were analyzed using SSPS (Statistical package for Social Science) version 20.0 (21). Presented prevalence estimates (n, \%) were calculated with the data and screening status to address different sampling probabilities and systematic nonresponse. The $\chi^{2}$-test was used in the case of dichotomous variables and a t-test was used for continuous variables. The significance level was set at 0.05 (two-tailed).

\section{Results}

Socio-demographic profile

The study was done on a sample size of 150 military personnel. All of them are Egyptian, Males and single according to the Egyptian law to enroll personnel in the military services. The age ranged from 18 to 30 years old with mean \pm SD of $23.7 \pm 3.2$ as it is the age of enrollment in the Egyptian mandatory military services. Based on the duration of service, the sample was taken 
the personnel early from the $1^{\text {st }}$ day of enrolling in the military services training. Regarding educational level, $68 \%$ of them were $\leq 12$ years education vs. $32 \%$ were $>12$ years education with $\mathrm{p}$ value (0.03). The non-smoker personnel (64.0\%) outnumbered the smoker personnel (36.0\%) ( $p=0.04)$ Table (1).

\begin{tabular}{|l|c|c|}
\hline \multicolumn{3}{|c|}{ Table 1: The Socio-demographic Characteristics of The Military Personnel } \\
\hline $\begin{array}{l}\text { The Socio-demographic } \\
\text { Characteristics }\end{array}$ & $\%$ & p Value \\
\hline $\begin{array}{c}\text { Nationality } \\
\text { - Egyptian }\end{array}$ & $100.0 \%$ & \\
- Non-Egyptian & $0.0 \%$ & \\
\hline $\begin{array}{l}\text { Gender } \\
\text { - Males }\end{array}$ & $100.0 \%$ & \\
\hline Age: Mean \pm SD & $0.0 \%$ & \\
\hline Marital Status & $23.76 \pm 3.266$ & \\
- Single & $100.0 \%$ & \\
\hline$\quad$ Married & $0.0 \%$ & \\
\hline Education & $68.0 \%$ & $0.03 *$ \\
$\quad 12$ years & $32.0 \%$ & \\
$>12$ years & $36.0 \%$ & $0.04 *$ \\
\hline Smoking & $64.0 \%$ & \\
- Smokers & Non-Smokers & \\
\hline * means statistically significant as p value $<0.05$. & \\
All the sample personnel are Egyptian, males and single. & \\
\hline
\end{tabular}

Table (2) shows the clinical characteristics of the studied group as it shows the mean \pm SD of different psychiatric symptoms according to the SCL-90-R and the mean \pm SD in the score of The Burnout Syndrome (31.79 \pm 16.81$)$ and The Social Readjustment Scale (363.91 \pm 201.66$)$. The psychiatric symptoms mean \pm SD was as follows: Somatization (54.44 \pm 11.51 ), Obsession and Compulsion (54.26 \pm 12.55$)$, Interactive Sensitivity (54.26 \pm 12.55$)$, Depression (54.95 \pm 12.56), Anxiety (55.62 \pm 11.67$)$, Hostility (55.53 \pm 13.04$)$, Phobia (58.29 \pm 14.32$)$, Paranoid Ideation (56.66 12.89 ) and Psychoticism (54.89 \pm 12.18 ). Table (3) shows that $28.7 \%$ of the sample had high scores on the $\mathrm{MBI}$ emotional exhaustion component of BOS, 30.7\% had high scores on the depersonalization component, and $58.7 \%$ had high scores on the personal satisfaction component. High burnout in the personal satisfaction subscale means a low score, that is mean, a low personal satisfaction. Regarding the total score in $\mathrm{MBI}$, Burnout Syndrome was found to be severe in $26 \%$ of the sample, Moderate in $34.7 \%$ and Low in $39.3 \%$. The most common psychiatric symptoms among the military personnel during early enrollment in the service according to CL-90 are anxiety, paranoid ideations, phobia and psychoticism (52.2, 46.5, 40.5 and $37.5 \%$, respectively, which were highly statistically significant) then, interactive sensitivity and depression ( 31.5 and $28.5 \%$, respectively, which were statistically significant) and the least common are somatization, obsessive compulsive and hostility (19.5, 18.0 and 16,5, respectively, which were not statistically significant), as shown in Table (4). Correlation analysis showed positive significant highly correlations between social readjustment scale scores and anxiety score $(p=0.003)$, phobia score $(p=0.006)$, paranoid ideation score $(p=$ 
$0.001)$ and psychoticism score $(p=0.002)$, and positive correlations with interactive sensitivity score $(p=0.022)$ and psycho-logical burnout scale score $(p=0.046)$, as shown in Table (5). Table (6) shows a linear regression analysis that conducted for predicting the social readjustment scale using the studied variables. Social readjustment level was plotted against each variable. Visual inspection of these plots indicated a linear relationship between the variables. There was homoscedasticity and normality of the residuals. Paranoia, depression, and anxiety statistically significantly predicted social readjustment scale with $(p<0.001)$.

\begin{tabular}{|l|c|}
\hline \multicolumn{2}{|c|}{$\begin{array}{c}\text { Table 2: The Clinical Characteristics of } \\
\text { The Military Personnel }(\mathrm{n}=150)\end{array}$} \\
\hline Clinical Characteristics & Mean \pm SD \\
\hline Somatization & $54.44 \pm 11.51$ \\
\hline Obsession \& Compulsion & $54.26 \pm 12.55$ \\
\hline Interactive Sensitivity & $54.26 \pm 12.55$ \\
\hline Depression & $54.95 \pm 12.56$ \\
\hline Anxiety & $55.62 \pm 11.67$ \\
\hline Hostility & $55.53 \pm 13.04$ \\
\hline Phobia & $58.29 \pm 14.32$ \\
\hline Paranoid Ideations & $56.66 \pm 12.89$ \\
\hline Psychoticism & $54.89 \pm 12.18$ \\
\hline Psychological Burnout Scale & $31.79 \pm 16.81$ \\
\hline Social Readjustment Scale & $363.91 \pm 201.66$ \\
\hline
\end{tabular}

\section{Discussion}

Our study was designed to assess the burnout, psychiatric symptoms, and social adjustment among military personnel in early military services. Mental health problems for the military context have become an important topic of research. The military culture can be characterized by its combat oriented, self-reliant masculine-warrior ethos ${ }^{(22)}$. In the context of health behaviors, internalizing the ideological position that men should be tough, competitive and emotionally inexpressive can have detrimental effects on a man's physical and mental health(23). Soldiers do dangerous and stressful work, and military personnel have an elevated risk of suffering from stress-related disorders following military deployment. The risks of developing other psychological disorders such as depression, anxiety, and alcohol abuse are also higher ${ }^{(24)}$. In this cross-sectional study, the sample was obtained from Mental Health
Military Hospital serving the soldiers recently enrolled in the military services through their military training units from all over Egypt during one-year period. The present study was designed to assess the burnout, psychiatric symptoms and social adjustment among military personnel in early military services. All the study sample are Egyptian, Males and single according to the Egyptian law to enroll personnel in the military services. The age ranged from 18 to 30 years old with mean \pm SD of $23.7 \pm 3.2$, as it is the age of enrollment in the Egyptian mandatory military services. Based on the duration of service, the sample was taken the personnel early from the 1st day of enrolling in the military services training. Most of them were $\leq 12$ years education (68\%) and non-smoker personnel (64.0\%). Our study showed that the most common psychiatric symptoms among the military personnel during early enrollment in the service according to SCL-90 are anxiety, 
paranoid ideations, phobia and psychoticism $(52.2 \%, 46.5 \%, 40.5 \%$ and $37.5 \%$, respectively, which were highly statistically significant) then, interactive sensitivity and depression (31.5\% and $28.5 \%$, respectively, which were statistically significant) and the least common are somatization, obsessive compulsive and hostility (19.5\%, 18.0\% and $16,5 \%$, respectively, which were not statistically significant). This may be because military personnel work in workplaces that are exposed to many stress factors.

\begin{tabular}{|c|c|c|c|}
\hline \multicolumn{4}{|c|}{$\begin{array}{c}\text { Table 3: The Burnout Syndrome of The Military Personnel } \\
\text { according to The Maslach Burnout Inventory }\end{array}$} \\
\hline \multicolumn{2}{|l|}{ Maslach Burnout Score } & \multicolumn{2}{|c|}{ No. $(\%)$} \\
\hline Maslach Burnout Subscale & High & Mo & Low \\
\hline Emotional Exhaustion $^{1}$ & $43(28.7 \%)$ & $53(3$ & $54(36.0 \%)$ \\
\hline Depersonalization $^{2}$ & $46(30.7 \%)$ & $60(40.0 \%)$ & $44(29.3 \%)$ \\
\hline Personal Satisfaction 3 & $88(58.7 \%)$ & $36(24.0 \%)$ & $26(17.3 \%)$ \\
\hline Total Score & $39(26.0 \%)$ & $52(34.7 \%)$ & $59(39.3 \%)$ \\
\hline \multicolumn{4}{|c|}{$\begin{array}{l}1 \text { high (score }>27) \text { moderate }(\text { score } 17-26) \text { low }(\text { score }<16), 2 \text { high (score }>13) \text {, } \\
\text { moderate }(\text { score } 7-12) \text {, low }(\text { score }<6) .3 \text { high }(\text { score }<31) \text {, moderate }(\text { score } 38-32) \text {, } \\
\text { low }(\text { score }>34 \text { ), High burnout in the personal satisfaction subscale means a low } \\
\text { score, that is mean, a low personal satisfaction. }\end{array}$} \\
\hline
\end{tabular}

There are complex work tasks in military environment that require special conditions of work. There are many factors which cause military personnel stressful from work that include everyday military training, unpredictable working hours, constant need for overtime and need to move to another units or city. Mismatch between high job requirements and individual potentials frustrate them and make them dissatisfied and can be the source of stress.

\begin{tabular}{|l|l|l|}
\hline \multicolumn{3}{|c|}{ Table 4: Prevalence of Psychiatric Symptoms } \\
According to Symptom Checklist-90 among The Military Personnel \\
\hline \multirow{2}{*}{ Psychiatric Symptoms } & The Studied Group $(\mathrm{n}=150)$ \\
\cline { 2 - 3 } & 19.5 & $\mathrm{p}$ \\
\hline Somatization & 18.0 & 0.11 \\
\hline Obsession \& Compulsion & 31.5 & 0.17 \\
\hline Interactive sensitivity* & 28.5 & 0.02 \\
\hline Depression & 52.5 & 0.001 \\
\hline Anxiety** & 16.5 & 0.19 \\
\hline Hostility & 40.5 & 0.004 \\
\hline Phobia** & 46.5 & 0.002 \\
\hline Paranoid Ideations** & 33.0 & 0.007 \\
\hline Psychoticism** & \multicolumn{2}{|}{} \\
\hline * Statistically significant when $p<0.05$. & & \\
** Highly statistically significant when $\mathrm{p}<0.01$. &
\end{tabular}

There are long-term pressures of working and negative way of dealing with the stressor is associated with anxiety ${ }^{(25)}$. This study showed that $28.7 \%$ of the sample had high scores on the $\mathrm{MBI}$ emotional exhaust- tion component of BOS, 30.7\% had high scores on the depersonalization component, and $58.7 \%$ had high scores on the personal satisfaction component. High burnout in the personal satisfaction sub-scale 
means a low score, that is mean, a low personal satisfaction. Regarding the total score in $\mathrm{MBI}$, Burnout Syndrome was found to be severe in $26 \%$ of the sample, Moderate in $34.7 \%$ and Low in $39.3 \%$. A study by Adler et al. carried on active duty and activate deserve component U.S. ser vice members deployed across Afghanistan showed that $9.3 \%$ reported feeling all three symptoms of depersonalization a few times/month or more frequently ${ }^{(26)}$. For the emotional exhaustion subscale, $30.1 \%$, reported feeling all three symptoms of exhaustion a few times/month or more.

\begin{tabular}{|c|c|c|c|}
\hline Factors & $\begin{array}{l}\text { Correlation } \\
\text { Coefficient }\end{array}$ & $95 \% \mathrm{Cl}$ & $\mathrm{p}$ \\
\hline Age & 0.065 & $-0.096,0.223$ & 0.426 \\
\hline Somatization & 0.147 & $-0.014,0.300$ & 0.073 \\
\hline Obsession \& Compulsion & 0.126 & $-0.034,0.281$ & 0.123 \\
\hline Interactive sensitivity* & 0.187 & $0.028,0.337$ & 0.022 \\
\hline Depression & 0.058 & $-0.103,0.217$ & 0.477 \\
\hline Anxiety** & 0.241 & $0.084,0.386$ & 0.003 \\
\hline Hostility & 0.156 & $-0.005,0.308$ & 0.057 \\
\hline Phobia** & 0.221 & $0.063,0.369$ & 0.006 \\
\hline Paranoid Ideations** & 0.279 & $0.125,0.421$ & 0.001 \\
\hline Psychoticism** & 0.250 & $0.093,0.394$ & 0.002 \\
\hline Psychological Burnout Scale* & 0.163 & $0.003,0.315$ & 0.046 \\
\hline
\end{tabular}

Overall, 33.3\% scored high on at least one of the two subscales. Another study which investigated burnout syndrome and anxiety on 311 military personnel reported that Emotional exhaustion (EE) was highest in military personnel under 30 years old. Also showed that anxiety increased with age and that it was the highest in military personnel older than $40^{(27)}$. A study carried in 20 healthy participants working in military in the state of Qatar showed that $40 \%$ of the sample had high scores on the $\mathrm{MBI}$ emotional exhaustion component of BOS, $40 \%$ had high scores on the depersonalization component and $60 \%$ had high scores on the personal satisfaction component ${ }^{(28)}$. Emotional exhaustion is the main cause and the core dimension of burnout syndrome which result from the discrepancy between expectations at work and the individual's ability to satisfy it ${ }^{(29)}$. Emo- tional exhaustion has bad health consequences(30) Military personnel show-ed burnout when job satisfaction decreased due to the financial and social effects and the damaging impact of burnout on physical or psychological aspect. Negative reaction involves emotional focus, slow reaction or decrease ability to solve the problem $^{(31)}$. The correlation analysis of our study showed positive significant highly correlations between social readjustment scale scores and anxiety score, phobia score, paranoid ideation score and psychoticism score. Positive correlations with interactive sensitivity score and psychological burnout scale score. Adler, et al. found that correlation between anxiety and burnout has shown that the level of anxiety was in connection of increase the emotional exhaustion and depersonalization and decrease of personal accomplishment, which 
is consistent with the results of other studies ${ }^{(3)}$. They also found that emotional exhaustion and depersonalization were positively and significantly related to professional stressors and negatively and significantly associated with self-care, team care, health-promoting leadership, and general leadership. There was no significant correlation between length of time deployed and the two burnout facets. Our study showed a linear regression analysis that conducted for predicting the social readjustment scale using the studied variables.
The study found that paranoia, depression, and anxiety statistically significantly predicted social readjustment scale. Pflanz and Sonnek identified the prevalence of reported occupational stress among military personnel. They concluded that more than one-quarter of this sample of military personnel reported suffering from significant work stress and a significant number of these individuals suffered serious emotional distress. They suggested that work stress may be a significant occupational health hazard in the US military(32).

\begin{tabular}{|c|c|c|c|c|c|c|}
\hline $\begin{array}{r}\text { Table 6: } \\
\text { Regressior } \\
\text { Other Stuc }\end{array}$ & $\begin{array}{l}\text { Analys } \\
\text { d Fact }\end{array}$ & $\begin{array}{l}\text { of Social Reac } \\
\text { s among The }\end{array}$ & $\begin{array}{l}\text { stment R } \\
\text { litary Per }\end{array}$ & $\begin{array}{l}\text { g S S } \\
\text { nnel }\end{array}$ & & \\
\hline Social Re-adjustment Scale & $\mathrm{B}$ & $95 \% \mathrm{Cl}$ for $\mathrm{B}$ & Constant & $\mathrm{R} 2$ & $\mathrm{~F}$ & $P$ \\
\hline Paranoia & 5.697 & $2.236,9.159$ & \multirow{3}{*}{118.913} & \multirow{3}{*}{$13.8 \%$} & \multirow{3}{*}{7.81} & \multirow{3}{*}{$<0.001$} \\
\hline Depression & -5.529 & $-9.156,-1.901$ & & & & \\
\hline Anxiety & 4.063 & $0.347,7.778$ & & & & \\
\hline
\end{tabular}

\section{Conclusion}

We can conclude that military personnel have a high level of burnout, early during enrollment in the military services. The most common psychiatric symptoms are anxiety, paranoid ideations, phobia, and psychoticism then, interactive sensitivity and depression. These symptoms can be considered predictors of their burnout. Psychological care especially the social readjustment mechanisms are of paramount importance and mandatory in this early period of enrollment in the military services.

\section{Limitations}

As the study was carried out in a small sample, it needs to be replicated on a large study sample.

\section{Implications}

1- Based on the findings of association between certain psychological symptoms and high burnout, we can suggest that psychological assessment can be made as a part of enrolled tests in military services. 2It is useful to assess stress, personality, and coping methods at multiple points during the service to recognize maladaptive behavior and thus, take necessary corrective action. 3- Training courses can be conducted to teach positive coping techniques to reduce mental stress in military services.

\section{References}

1. Keller RT, Greenberg N, Bobo WV, et al. Soldier peer mentoring care and support: bringing psychological awareness to the front. Milit Med 2005; 170: 355-61.

2. Hoge CW, Lesikar SE, Guevara R, et al. Mental disorders among U.S. military personnel in the 1990s: association with high levels of health care utilization and early military attrition. Am J Psychiatry 2002; 159: 1576-83.

3. Adler AB, Adrian AL, Hemphill CM, et al. Professional stress, and burnout in US military medical personnel deployed to Afghanistan. Military Medicine 2017; 182(3): e1669. 
4. Rao GP, Moinuddin K, Sai PG, Sarma E, Sarma A, Rao AS. A study of stress and psychiatric morbidity in central industrial security force. Indian J Psychol Med. 2008; 30:39-47.

5. Lipp ME. Stress and quality of life of senior Brazilian police officers. Span J Psychol 2009; 12: 593-603.

6. Arial M, Gonik V, Wild P, Danuser B. Association of work-related chronic stressors and psychiatric symptoms in a Swiss sample of police officers; a cross sectional questionnaire study. Int Arch Occup Environ Health 2010; 83: 323-31.

7. Bano B. Job stress among police personnel. IPEDR 2011; 4: 290-3.

8. Amin A. and Mohammad A. Resilience, burnout, and role stress among military personnel. Middle East Current Psychiatry 2012; 19: 123-129.

9. Kaur, R; Chodagiri, V. and Reddi, N. A psychological study of stress, personality and coping in police personnel. Indian J Psychol Med,2013; 01 Apr, 35(2): 141-147. DOI: 10.4103/0253-7176.116240 PMID: 24049224 PMCID: PMC3775045.

10. WHO World Health Organization; ICD10: International classification of diseases. Geneva.1994.

11. Kraft U. Burned out. Sci Am Mind 2006; 7: 28-33.

12. Beer J, Beer J. Burnout and stress, depression, and self-esteem of teachers. Psychol Rep 1992; 71 (3 Pt 2): 1331-1336.

13. Reda MM, Mabrouk A. Burnout syndrome in burn unit in comparison to plastic surgery unit in Ain-Shams University. Curr Psychiatr 2004; 11: 33-35.

14. Carver CS, Connor-Smith J. Personality, and coping. Annu Rev Psychol 2010; 61: 679-704.

15. Cabarkapa M, Korica V, Rodjenkov S. Personal traits, and a sense of job-related stress in a military aviation crew. Vojnosanit Pregl. 2011; 68: 143-9.

16. Peng AC, Riolli LT, Schaubroeck J, et al. A moderated mediation test of personality, coping, and health among deployed soldiers. Journal of Organizational Behavior 2012; 33: 512-530.
17. Maslach, C.; Jackson, S.E.; Leiter, M.P. Maslach Burnout Inventory Manual (Fourth Edition). Menlo Park, CA: Mind Garden 2016.

18. Derogatis L R. Symptom Checklist-90Revised (SCL-90-R), Pearson: Clinical Psychology. Pearson Education, Inc 2016.

19. Al-Behairy, AA. Symptom Checklist-9oRevised (SCL-90-R), Arabic Form. Cairo, Egypt: Al-Nahda Al-Messria Library 1984.

20. Holmes TH and Rahe RH .The social readjustment rating scale. Journal of Psychosomatic Research 1967; 1: 213-218.

21. SPSS. Version 20.0 Command Syntax Reference. Chicago, Illinois, USA: SPSS Inc 2009.

22. Dunivin, K. O. Military culture: Change and continuity. Armed Forces \& Society,1994; Vol. 20, No. 4, p. 533.

23. Courtenay, W. H. Constructions of Masculinity and Their Influence on Men's Well-Being - Social Science \& Medicine,2000; Vol. 50, No. 10, pp. 13851401.

24. Smith TC, Wingard DL, Ryan MA, et al. PTSD prevalence, associated exposures, and functional health outcomes in a large, population-based military cohort. Public Health Rep 2009; 124(1): 90-102.

25. Dedić $G$, Kostić $P$. Causes of frustration of soldiers in adaptation period on military environment. Vojnosanit Pregl 2001; 58(6): 621-630.

26. Amy B. Adler, Amanda L. Adrian, COL Marla Hemphill, CAPT Nicole H. COL Maurice L. Sipos, LTC Jeffrey L. Thomas. Professional Stress and Burnout in U.S. Military Medical Personnel Deployed to Afghanistan, Military Medicine J .2017;182, 3/4:e1669.

27. Aleksandra R. Vojvodic, Gordana Dedic. Correlation Between Burnout Syndrome and Anxiety in Military Personnel,Serbian Journal of Experimental and Clinical Research.2018; 21(1).DOI: 10.2478/sjecr-2018-0004.

28. Amin A. Resilience, burnout, and role 
stress among military personnel, Middle East Current Psychiatry,2012; 19: 123-129.

29. Dedic G. Burnout syndrome. Vojnosanit Pregl 2005; 62(11): 851-855

30. Nowakowska I, Rasińska R, Głowacka $D$. The influence of factors of work environment and burnout syndrome on self-efficacy of medical staff. Annals of Agricultural and Environmental Medicine. 2016;23(2): 304-9
31. Tarcan M, Hikmet N, Schooley B, Top $M$, Tarcan GY. An analysis of the relationship between burnout, socio-demographic and workplace factors and job satisfaction among emergency department health professionals. Appl Nurs Res. 2017;34: 40-47

32. Pflanz S, Sonnek S. Work stress in the military: prevalence, causes, and relationship to emotional health. Milit Med 2002; 167: 877-82. 